\title{
Perception of OSCE as An Assessment Tool in Undergraduate Students of Private Medical College in Karachi, Pakistan
}

\author{
SABA PARIO ${ }^{1}$, SHAISTA BASHIR ANWAR ${ }^{2}$, ZAFAR HALEEM BALOCH $^{3}$, SAIRA GHAFOOR ${ }^{4}$, SHAZIA AFTAB $^{5}$, SADIA $^{2}$ \\ RASHID ${ }^{6}$, SADIA SUBOOHI ${ }^{7}$, ZAHRA SALAUDDIN ${ }^{8}$ \\ ${ }^{1}$ Assistant Professor Obs \& Gyn department, United Medical and Dental College, Karachi \\ ${ }^{2}$ Senior Registrar Obs \& Gyn department, United Medical and Dental College, Karachi \\ ${ }^{3}$ Senior Lecturer Anatomy Department, Jinnah Sindh Medical University, Karachi \\ ${ }^{4,5,6}$ Associate Professor Obs \& Gyn department, Jinnah Medical College, Korangi Karachi \\ ${ }^{7}$ Professor Obs \& Gyn department, United Medical and Dental College, Karachi \\ ${ }^{8}$ House Officer, United Medical and Dental College, Karachi \\ Corresponding Author: Dr. Saba Pario, Assistant Professor Obs \& Gyn department, United Medical and Dental College, Karachi, Email: \\ drsabapario@gmail.com, Cell No.+923363036187
}

\begin{abstract}
OBJECTIVE: To explore the perception of undergraduate students of United Medical and dental college towards objective structured clinical examination as an assessment tool.

MATERIAL \& METHODS: A cross-sectional observational study included undergraduate medical students,

RESULTS: 153 students who completely filled the proforma were included in study among them $31 \%$ were male and $69 \%$ were females. Mostly agreed that stations in OSCE were simple and easily interpretable and assessed practical skills thoroughly. Majority of students accepted that skills inquired were taught in clinics, stations were according to course and stations were appropriately timed. $66 \%$ confirmed that adequate instructions were provided before exam. $84.31 \%$ believed that OSCE is preferable to viva. $57.51 \%$ of candidates stated that examiners during OSCE were attentive and gracious but $20.91 \%$ objected it, while $21.57 \%$ remained neutral.

Almost half of examinees labelled it as comprehensive clinical assessment .Overall, $67.97 \%$ perceived OSCE as demanding and tough assessment. Finally views of students for statement that OSCE is unbiased, reliable and valid were positive in $50.32 \%$. There was a significant difference in the opinion of male and female( $p$-value is less than 0.05) in statement that OSCE thoroughly assessed practical skills, stations were according to course of instruction, Adequate instructions were provided before exam, superior and preferable to viva, assists in improvement of clinical skills, demanding and tough and finally OSCE was unbiased, reliable and valid

CONCLUSION: OSCE was perceived as fair, comprehensive, un-biased format of examination but believed it was more stressful than traditional examination methods.

KEY WORDS: Assessment, Attitude, OSCE, Perception, Undergraduate Medical students.
\end{abstract}

\section{INTRODUCTION}

Proper evaluation of knowledge, competence and proficiency of undergraduate medical students is an important part of their training and assessments and examination ${ }^{1}$. Conventionally undergraduate students are evaluated through theoretical written exam, viva and their clinical performance. OSCE is currently practiced globally to deliver an appropriate means for constructive and summative assessment. ${ }^{2}$

OSCE is a clinical examination tool that assesses the students' capability to utilize their knowledge and skills for diagnosis, management and proper communication as well as counseling of patients. 3,4

OSCE involves multiple stations for history taking, physical examination, clinical methods, communication skills, interpretation of investigations, diagnosis and management in a specified time. ${ }^{5}$

Stations may be interactive, static and of rest. In interactive stations candidate has to deal with real or simulated patients and are assessed by examiner, who marks them according to provided checklist. ${ }^{6}$ While at static stations there may be any clinical scenario, instruments, investigations provided for interpretation and diagnosis. OSCE is considered to be an objective way of judgment that is equitable. non biased, limits element of luck, and reflects the actual scenarios experienced by medical practitioners in practical life . Contrarily conduction of OSCE is considered to be associated with more consumption of time and cost due to need of purposeful space, multiple examiners, patients and coordinators. ${ }^{7}$

Students perception and feedback is an integral component of OSCE, it is undertaken mainly to know overall perspective of candidates. ${ }^{8,9}$ This study was conducted in a private medical college of metropolitan city to explore the perception of undergraduate medical students towards OSCE as a positive criticism for further improvement in planning of upcoming examinations as it is an integral component of current educational system.

\section{MATERIAL \& METHODS}

This cross-sectional study included 153 undergraduate medical students of United Medical \& Dental college karachi, who appeared in the clinical evaluation at end of semester in April-May 2019. An ethical approval was attained from ethical Review Board of institute to conduct the study.

All final year (Semester IX- clinical) students (172) enrolled in General Surgery, obstetrics \& Gynecology, Medicine and Pediatric module of 2019 session were included in study to assess their perception towards objective structured clinical examination.

The inclusion criteria was completion of clinical rotation in all four above mentioned clinical subjects and completion of proforma at end of OSCE. Students those did 
not completed their clinical rotation training or not completely filled the proforma were excluded from the study.

OSCE was conducted in four days, each discipline was allocated one day, and students were segregated in groups involving evaluation of almost 40 undergraduates per day. Each group was further divided into two shifts for intention of convenience, availability of staff and space. Detail orientation was provided to candidates before start of exam. Fourteen stations were arranged in OSCE exam, including interactive, static and rest stations, time duration at each station was 5 minutes. Candidate had to deal with real or simulated patients during an interactive station in front of examiner, who had answer key checklist for marking. While at static stations clinical scenario, investigations for interpretation and diagnosis, clinical skills were provided which students had to answer on given sheets and insert in the closed boxes kept at every station before leaving from station. Candidates were rotated in clockwise fashion in the OSCE circuit. A standardized criterion-based scoring format was used for marking at each station

Just after completion of OSCE, students were briefed regarding objective and importance of this study. Questionnaires were provided to students to assess their feedback and perception regarding OSCE. Students completed the forms in presence of investigator to explain any difficulty, if encountered and returned it before leaving examination hall. Anonymity of candidates' identification was reassured to them. Questionnaire was filled and returned by all undergraduate medical students, but 19 of them were incomplete so excluded therefore $n=153$. Questionnaire was designed to gather information from students regarding OSCE, composed of following feedback items, stations in OSCE were simple and easily interpretable, OSCE thoroughly assessed practical skills, skills inquired were taught in clinics, OSCE stations were according to course of instruction, OSCE stations were appropriately timed, Adequate instructions were provided before exam, OSCE is superior and preferable to viva, examiners during OSCE were attentive and gracious, OSCE is comprehensive clinical assessment, OSCE assists in improvement of clinical skills, OSCE was demanding and tough, finally OSCE is unbiased, reliable and valid. Response were rated by students for each statement as strongly agree, agree, no idea, disagree or strongly disagree.

DATA ANALYSIS: The data was entered and analyzed in Statistical Package for Social Science (SPSS), version 19 and the results were expressed in proportions and percentages. The data was stratified by males and females and statistical significance determined. $P<0.05$ was used for significance.

\section{RESULTS}

One hundred and seventy two students were inquired to determine their attitude and perception towards objective structured clinical examination, out of 172 questionnaires 153 were completely filled and remaining were incomplete so excluded from study. Out of 153, $106(69 \%)$ students were females and $47(31 \%)$ were males. (FIGURE I)
Among 153 students, $44(28.76 \%)$ strongly agreed, $58(37.90 \%)$ agreed, $6(3.92 \%)$ had no idea, $28(18.30 \%)$ disagreed and $17(11.11 \%)$ strongly disagreed that stations in OSCE were simple and easily interpretable. $24.84 \%$ and $47.05 \%$ strongly agreed and agreed respectively that OSCE assessed practical skills thoroughly. Regarding view of students that skills inquired were taught in clinics majority of them that is $18.95 \%$ strongly agreed and $44.44 \%$ agreed and OSCE stations were according to course of instruction $28.10 \%$ strongly agreed and $46.40 \%$ agreed.

$76.47 \%$ (strongly agreed \& agreed) accepted that stations were appropriately timed, in contrast $4.58 \%$ strongly disagreed and $5.22 \%$ disagreed from same statement, while $13.73 \%$ were not sure. $66.01 \%$ confirmed that adequate instructions were provided before exam, but $21.57 \%$ were in disagreement to it. Most $(84.31 \%)$ of them believed that OSCE is superior and preferable to viva. $57.51 \%$ (strongly agreed \& agreed) of candidates stated that examiners during OSCE were attentive and gracious but $20.91 \%$ (strongly disagree \& disagree) objected it, while $21.57 \%$ remained neutral. $58.82 \%$ realized that OSCE is a comprehensive clinical assessment. $39.87 \%$ accepted that OSCE assists in improvement of clinical skills. $67.97 \%$ perceived OSCE as demanding and tough assessment. Finally views of students for statement that OSCE is unbiased, reliable and valid were positive in $50.32 \%$ (strongly agree \& agree), negative in $24.84 \%$ (strongly disagree \& disagree) and $24.84 \%$ remained neutral. (TABLE I)

Stratification with respect to Gender was conducted (TABLE II) and p-values calculated.

There was a significant difference in the opinion of male and female ( $p$-value is less than 0.05$)$ in statement that OSCE thoroughly assessed practical skills, stations were according to course of instruction, Adequate instructions were provided before exam, superior and preferable to viva, assists in improvement of clinical skills, demanding and tough and finally OSCE was unbiased, reliable and valid. Whereas the stratification showed that the opinions of both genders were almost same and the pvalue revealed that insignificant relation between male and female in remaining OSCE stations.

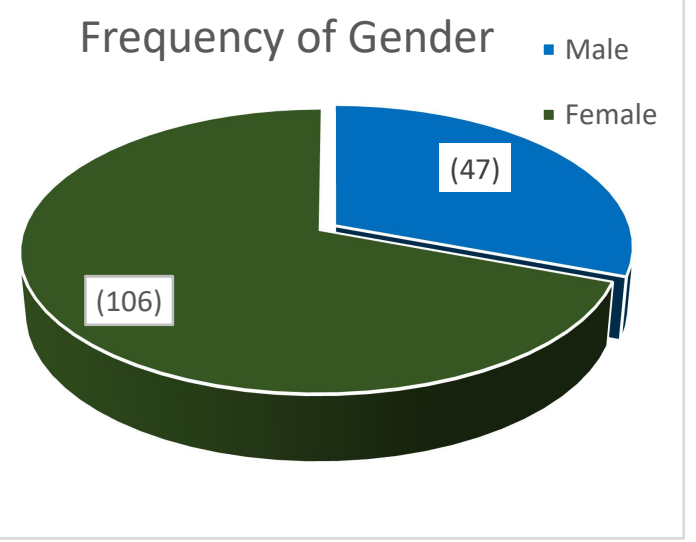

Figure 1 Frequency of Gender 
TABLE 1: Students attitude and perception towards OSCE.

\begin{tabular}{|c|c|c|c|c|c|}
\hline Statements & $\begin{array}{l}\text { Strongly Agree } \\
\mathrm{n}(\%)\end{array}$ & $\begin{array}{l}\text { Agree } \\
\mathrm{n}(\%)\end{array}$ & $\begin{array}{l}\text { No idea } \\
\mathrm{n}(\%)\end{array}$ & $\begin{array}{l}\text { Disagree } \\
\mathrm{n}(\%)\end{array}$ & $\begin{array}{l}\text { Strongly Disagree } \\
\mathrm{n}(\%)\end{array}$ \\
\hline stations in OSCE were simple and easily interpretable & $44(28.76 \%)$ & $58(37.90 \%)$ & $6(3.92 \%)$ & $28(18.30 \%)$ & $17(11.11 \%)$ \\
\hline OSCE thoroughly assessed practical skills & $38(24.84 \%)$ & $72(47.05 \%)$ & $12(7.84 \%)$ & $15(9.80 \%)$ & $16(10.46 \%)$ \\
\hline skills inquired were taught in clinics & $29(18.95 \%)$ & $68(44.44 \%)$ & $24(15.69 \%)$ & $18(11.76 \%)$ & $14(9.15 \%)$ \\
\hline OSCE stations were according to course of instruction, & $43(28.10 \%)$ & $71(46.40 \%)$ & $20(13.07 \%)$ & $12(7.84 \%)$ & $7(4.58 \%)$ \\
\hline OSCE stations were appropriately timed & $41(26.79 \%)$ & $76(49.67 \%)$ & $21(13.73 \%)$ & $8(5.22 \%)$ & $7(4.58 \%)$ \\
\hline Adequate instructions were provided before exam & $35(22.87 \%)$ & $66(43.14 \%)$ & $19(12.42 \%)$ & $17(11.11 \%)$ & $16(10.46 \%)$ \\
\hline OSCE is superior and preferable to viva & $51(33.33 \%)$ & $78(50.98 \%)$ & $9(5.88 \%)$ & $11(7.19 \%)$ & $4(2.61 \%)$ \\
\hline examiners during OSCE were attentive and gracious & $31(20.26 \%)$ & $57(37.25 \%)$ & $33(21.57 \%)$ & $14(9.15 \%)$ & $18(11.76 \%)$ \\
\hline OSCE is comprehensive clinical assessment & $37(24.18 \%)$ & $53(34.64 \%)$ & $33(21.57 \%)$ & $12(7.84 \%)$ & $18(11.76 \%)$ \\
\hline OSCE assists in improvement of clinical skills & $30(19.61 \%)$ & $31(20.26 \%)$ & $49(32.02 \%)$ & $18(11.76 \%)$ & $25(16.34 \%)$ \\
\hline OSCE was demanding and tough & $41(26.79 \%)$ & $63(41.18 \%)$ & $23(15.03 \%)$ & $15(9.80 \%)$ & $11(7.19 \%)$ \\
\hline OSCE is unbiased, reliable and valid & $33(21.56 \%)$ & $44(28.75 \%)$ & $38(24.84 \%)$ & $21(13.73 \%)$ & $17(11.11 \%)$ \\
\hline
\end{tabular}

TABLE 2: Stratification with Respect to Gender

\begin{tabular}{|c|c|c|c|c|c|c|c|c|}
\hline \multirow[b]{2}{*}{ Statement } & \multirow{2}{*}{\multicolumn{2}{|c|}{ Gender }} & \multicolumn{5}{|c|}{ Satisfaction Level } & \multirow[b]{2}{*}{ P-Value } \\
\hline & & & $\begin{array}{l}\text { Strongly } \\
\text { Agree }\end{array}$ & Agree & Undecided & Disagree & $\begin{array}{l}\text { Strongly } \\
\text { Disagree }\end{array}$ & \\
\hline \multirow{4}{*}{$\begin{array}{l}\text { Stations in OSCE were simple and easily } \\
\text { interpretable }\end{array}$} & \multirow{2}{*}{ Male } & Count & 3 & 9 & 1 & 21 & 13 & \multirow{4}{*}{0.592} \\
\hline & & $\%$ of Total & $2.0 \%$ & $5.9 \%$ & $0.7 \%$ & $13.7 \%$ & $8.5 \%$ & \\
\hline & \multirow{2}{*}{ Female } & Count & 14 & 19 & 5 & 37 & 31 & \\
\hline & & $\%$ of Total & $9.2 \%$ & $12.4 \%$ & $3.3 \%$ & $24.2 \%$ & $20.3 \%$ & \\
\hline \multirow{4}{*}{ OSCE thoroughly assessed practical skills } & \multirow{2}{*}{ Male } & Count & 0 & 6 & 3 & 21 & 17 & \multirow{4}{*}{0.022} \\
\hline & & $\%$ of Total & $0.0 \%$ & $3.9 \%$ & $2.0 \%$ & $13.7 \%$ & $11.1 \%$ & \\
\hline & \multirow{2}{*}{ Female } & Count & 16 & 9 & 9 & 51 & 21 & \\
\hline & & $\%$ of Total & $10.5 \%$ & $5.9 \%$ & $5.9 \%$ & $33.3 \%$ & $13.7 \%$ & \\
\hline \multirow{4}{*}{ skills inquired were taught in clinics } & \multirow[b]{2}{*}{ Male } & Count & 7 & 6 & 9 & 17 & 8 & \multirow{4}{*}{0.380} \\
\hline & & $\%$ of Total & $4.6 \%$ & $3.9 \%$ & $5.9 \%$ & $11.1 \%$ & $5.2 \%$ & \\
\hline & \multirow{2}{*}{ Female } & Count & 7 & 12 & 15 & 51 & 21 & \\
\hline & & $\%$ of Total & $4.6 \%$ & $7.8 \%$ & $9.8 \%$ & $33.3 \%$ & $13.7 \%$ & \\
\hline \multirow{4}{*}{$\begin{array}{l}\text { OSCE stations were according to course of } \\
\text { instruction, }\end{array}$} & \multirow[b]{2}{*}{ Male } & Count & 2 & 5 & 1 & 16 & 23 & \multirow{4}{*}{-0.001} \\
\hline & & $\%$ of Total & $1.3 \%$ & $3.3 \%$ & $0.7 \%$ & $10.5 \%$ & $15.0 \%$ & \\
\hline & \multirow{2}{*}{ Female } & Count & 5 & 7 & 19 & 55 & 20 & \\
\hline & & $\%$ of Total & $3.3 \%$ & $4.6 \%$ & $12.4 \%$ & $35.9 \%$ & $13.1 \%$ & \\
\hline & & Count & 4 & 5 & 4 & 21 & 13 & \\
\hline & Male & $\%$ of Total & $2.6 \%$ & $3.3 \%$ & $2.6 \%$ & $13.7 \%$ & $8.5 \%$ & \\
\hline OSCE statıons were appropriately tımed & & Count & 3 & 3 & 17 & 55 & 28 & 0.099 \\
\hline & Female & $\%$ of Total & $2.0 \%$ & $2.0 \%$ & $11.1 \%$ & $35.9 \%$ & $18.3 \%$ & \\
\hline & & Count & 4 & 9 & 0 & 26 & 8 & \\
\hline Adequate instructions were provided before & Male & $\%$ of Total & $2.6 \%$ & $5.9 \%$ & $0.0 \%$ & $17.0 \%$ & $5.2 \%$ & \\
\hline exam & & Count & 12 & 8 & 19 & 40 & 27 & 0.003 \\
\hline & Female & $\%$ of Total & $7.8 \%$ & $5.2 \%$ & $12.4 \%$ & $26.1 \%$ & $17.6 \%$ & \\
\hline & & Count & 6 & 8 & 3 & 19 & 11 & \\
\hline & Male & $\%$ of Total & $3.9 \%$ & $5.2 \%$ & $1.9 \%$ & $12.3 \%$ & $7.1 \%$ & \\
\hline OSCE is superior and preferable to viva & & Count & 0 & 3 & 6 & 59 & 40 & 0.001 \\
\hline & Female & $\%$ of Total & $0.0 \%$ & $1.9 \%$ & $3.9 \%$ & $38.1 \%$ & $25.8 \%$ & \\
\hline & Male & Count & 1 & 5 & 12 & 19 & 10 & \\
\hline examiners during OSCE were attentive and & & $\%$ of Total & $0.7 \%$ & $3.3 \%$ & $7.8 \%$ & $12.4 \%$ & $6.5 \%$ & \\
\hline gracious & Female & Count & 17 & 9 & 21 & 38 & 21 & 0.183 \\
\hline & & $\%$ of Total & $11.1 \%$ & $5.9 \%$ & $13.7 \%$ & $24.8 \%$ & $13.7 \%$ & \\
\hline & Male & Count & 3 & 2 & 7 & 23 & 12 & \\
\hline & & $\%$ of Total & $2.0 \%$ & $1.3 \%$ & $4.6 \%$ & $15.0 \%$ & $7.8 \%$ & \\
\hline OSCE Is comprehensive clinical assessment & Female & Count & 15 & 10 & 26 & 30 & 25 & 0.083 \\
\hline & & $\%$ of Total & $9.8 \%$ & $6.5 \%$ & $17.0 \%$ & $19.6 \%$ & $16.3 \%$ & \\
\hline & Male & Count & 2 & 9 & 11 & 17 & 8 & \\
\hline & & $\%$ of Total & $1.3 \%$ & $5.9 \%$ & $7.2 \%$ & $11.1 \%$ & $5.2 \%$ & \\
\hline OSCE assists in improvement of clinical skills & Female & Count & 23 & 9 & 38 & 14 & 22 & 0.001 \\
\hline & & $\%$ of Total & $15.0 \%$ & $5.9 \%$ & $24.8 \%$ & $9.2 \%$ & $14.4 \%$ & \\
\hline & Male & Count & 1 & 2 & 2 & 23 & 19 & \\
\hline & & $\%$ of Total & $0.7 \%$ & $1.3 \%$ & $1.3 \%$ & $15.0 \%$ & $12.4 \%$ & \\
\hline OSCE was demanding and tough & Female & Count & 10 & 13 & 21 & 40 & 22 & -0.004 \\
\hline & & $\%$ of Total & $6.5 \%$ & $8.5 \%$ & $13.7 \%$ & $26.1 \%$ & $14.4 \%$ & \\
\hline & Male & Count & 1 & 0 & 20 & 15 & 11 & \\
\hline & & $\%$ of Total & $0.7 \%$ & $0.0 \%$ & $13.1 \%$ & $9.8 \%$ & $7.2 \%$ & \\
\hline OSCE is unbiased, reliable and valid & Female & Count & 16 & 21 & 18 & 29 & 22 & 0.001 \\
\hline & & $\%$ of Total & $10.5 \%$ & $13.7 \%$ & $11.8 \%$ & $19.0 \%$ & $14.4 \%$ & \\
\hline
\end{tabular}

Applied Chi-Square test 


\section{DISCUSSION}

The results of current study express overall positive perception of undergraduate medical students towards objective structured clinical examination. They well agreed that stations in OSCE were simple and easily interpretable, assessed practical skills that were taught in clinics and were according to syllabus, which is in agreement with previous studies. 2,10 In contrast to it, study conducted by Siddiqui FG , 43\% students believed that the skills inquired in exam were explained in clinics. ${ }^{11}$

Regarding feedback for adequate time allowed at each station, most of examinee were satisfied, same observed in studies conducted by Khan $\mathrm{M}$ et al and Moeenuz-zafar et al ${ }^{2,12}$ but study conducted by Majumder et al reported that majority of the Students $(66.7 \%)$ needed more time at stations.

In justification of statement that adequate instructions were provided before exam, majority

$(66.01 \%)$ of candidates well agreed. This is in line with Khan $\mathrm{M}$ et al $^{2}$ and lqbal haider et $a{ }^{14}{ }^{14}$ but in disagreement with Siddiqui FG. ${ }^{11}$

In current study when inquired whether OSCE is preferable method of assessment and superior to conventional viva, $84.31 \%$ (strongly agree \& agree) were in favour to this statement. This is consistent with the findings reported by other studies where majority of students appreciated OSCE as an appropriate examination system compared to other conventional methods of examination. ${ }^{8}$ 15,16 while study conducted by Rahil $\mathrm{H}$ et al, $47 \%$ students preferred it over other forms of assessment. ${ }^{17}$

In this study $57.51 \%$ examinees believed that examiners during OSCE were attentive and gracious, but $21.57 \%$ remained neutral and $20.91 \%$ denied the fact. While Pratima jaiswal et al concluded that $38.8 \%$ of examinees stated that the examiners were polite and professional, and $37.6 \%$ were neutral for same statement. ${ }^{5}$ Study conducted by lqbal Haider et al concluded that Examiners have a tendency to get tired over time in a long OSCE leading to a decline in their ability to concentrate. ${ }^{18}$

In current study $58.82 \%$ students reported that OSCE is comprehensive clinical assessment and $39.87 \%$ thought that OSCE assists in improvement of their clinical skills (strongly agree \& agree), which is in accordance with previous work. ${ }^{2.5 .8}$. In study by Abidullah khan etal, $88 \%$ stated that exam was fair and comprehensive. ${ }^{8}$ In this series, $67.97 \%$ students declared that OSCE was demanding and tough, which is in agreement with Rahil $\mathrm{H}$ et al study in which $48 \%$ found it to be stressful, and $40 \%$ found it not easy. ${ }^{17}$ More high numbers were observed in other study in whom $94 \%$ believed that OSCE was stressful and mentally tougher. ${ }^{8}$ Similar results observed in other studies with candidates facing increased stress during OSCE were documented. ${ }^{11.16,19}$

Finally OSCE declared as unbiased, reliable and valid assessment tool in our study by $50.32 \%$ of students while $24.84 \%$ remained neutral and similar percentage $(24.84 \%)$ reported negatively.

Ninety-six percent considered OSCE as valid and reliable in Khan A et al study. ${ }^{8}$

Reliability, no bias and validity of OSCE appreciated by students in other studies as well. ${ }^{2.20 .21}$ This study was first of its kind from this private medical college located in metropolitan city, that included comprehensive set of questions and their stratification according to gender. Few limitations observed including relatively smaller sample size and inclusion of only final year students. Further studies are recommended in this regard, with a larger sample size, inclusion of students from all five years, perception of examiners, ${ }^{18}$ collection of data from multiple institutes for comparison and to have better assessment outcome regarding OSCE as tool.

\section{CONCLUSION}

OSCE was perceived as unbiased, reliable and valid tool of assessment and examination of under graduate medical students. Negative perception like stress and difficulty can be improved by better orientation and taking regular feedback from students.

\section{Conflicts of Interest: None}

\section{REFRENCES}

1. Elfaki OA and Al-Humayed S. Medical Students' Perception of OSCE at the Department of Internal Medicine, College of Medicine, King Khalid University, Abha, KSA. JCPSP. 2016, Vol. 26 (2): 158-159.

2. Khan M, Noor SM, Siraj MU. Students' perceptions of OSCE in dentistry: A study from Khyber College of Dentistry, Pakistan. Adv Health Prof Educ. 2015;1(1):30-36.

3. Nasir AA, Yusuf AS, Abdur-Rahman LO, Babalola OM, Adeyeye AA, Popoola AA, et al. Medical students' perception of objective structured clinical examination: a feedback for process improvement. JSE .2014;71:5:701-06.

4. Edward, M. I., F. Okanlawon . Perception of objective structured clinical examination and traditional practical examination in assessment of nursing students clinical competencies by nursing students in south west Nigeria. IJMRR 2016;4(8):1340-50.

5. Jaiswal P, Mehta RK. Medical students' perception regarding objective structured clinical examination in medical college, Chitwan. JCMC. 2019; 9 (27): 52-60.

6. Akhtar N, AyazSB, Khan AA, Qamar K. Objective structured clinical examination (OSCE) - A better dimension to measure clinical competencies. PAFMJ. 2017; 67 (4): 677-80.

7. Khan M, Haider I, Humayun M, Khan A. Objective structured clinical examination (OSCE)

8. as a tool of conducting examination. J Med Sci. 2016; 24: (4) 273-274.

9. Khan A, Ayub M, Shah Z. An audit of the medical students perceptions regarding objective structured clinical examination. Education Research International. 2016 Jan $1 ; 2016$.

10. Alaidarous S, Mohamed TA, Masuadi E, Wali S, AlMalki A. Saudi Internal Medicine Residents' Perceptions of the Objective Structured Clinical Examination as a Formative Assessment Tool. Health Professions Education 2016; 2:121-9.

11. Khursheed I, Usman Y, Usman J. Students' feedback of objectively structured clinical examination: a private medical college experience. J Pak Med Assoc 2007; 57:148-9.

12. Siddiqui FG. Final year MBBS students' perception for observed structured clinical examination. JCPSP 2013; 23:20-4.

13. Moeen-uz-zafar, Al Shammari O, Aljarallah B . Evaluation of Interactive OSCE for Medical Students in the Subject of Medicine; Reliability and Validity in the Setting of Internal vs. External Examiners. Ann Public Health Res 2015; 2(4): 1030. 
14. Majumder AA, Kumar A, Krishnamurthy K, Ojeh N, Adams OP, Bidyadhar SA. An evaluative study of objective structured clinical examination (OSCE): students and examiners

15. perspectives. AMEP. 2019:10 387-397.

16. Haider I, Khan A, Imam M, Ajmal F, Khan M, Ayub M. Perceptions of final professional

17. MBBS students and their examiners about objective structured clinical examination (OSCE): a combined examiner and examinee survey. J Med Sci. 2016; 24: (4) 206-211.

18. Khan AS, Javaeed A, Rasheed RA, Ghauri SK, Mustafa KJ. Perceptions of Undergraduate Medical Students regarding Objective Structured Practical Examination and Objective Structured Clinical Examination as an Assessment Method. IJP. 2016; 14(2)60-65.

19. Khorashad AK, Salari S, Baharvahdat H, Hejazi S, Lari SM, Salari $M$ et al. The Assessment of Undergraduate Medical Students' Satisfaction Levels With the Objective Structured Clinical Examination. Iran Red Crescent Med J. 2014;16(8):e13088.
20. Raheel H, Naeem N. Assessing the Objective Structured Clinical Examination: Saudi family medicine undergraduate medical students' perceptions of the tool. J Pak Med Assoc 2013;10:1281-84

21. Haider I, Badshah A, Khan AR, Abidullah. Fatigue level of examiners during objective structured clinical examination (osce); a single institution based survey. J Med Sci. 2018; 26: (3) 207-210.

22. Bevan J, Russell B, Marshal B. A new approach to OSCE preparation -PrOSCEs. BMC Medical Education (2019) 19:126

23. Shitu B, Girma T. Objective structured clinical examination (osce): examinee's perception at department of pediatrics and child health, Jimma university. Ethiop J Health Sci. 2008; 18(2):47-52.

24. Bhat VS, Prasad K, Bhat SP. A Study of effectiveness of OSCE in the formative and summative assessment of medical students- a student centered study. IERJ. 2016(3) 